Цяо Дун, Люй Имин, Чжао Тин. К вопросу о системе финансового менеджмента и управления хозяйственной деятельностью больниц во время эпидемии COVID-19

Научная статья

УДК 338.26

DOI 10.18101/2304-4446-2021-4-91-99

\title{
К ВОПРОСУ О СИСТЕМЕ ФИНАНСОВОГО МЕНЕДЖМЕНТА И УПРАВЛЕНИЯ ХОЗЯЙСТВЕННОЙ ДЕЯТЕЛЬНОСТЬЮ БОЛЬНИЦ ВО ВРЕМЯ ЭПИДЕМИИ COVID-19
}

(С) Цяо Дун

обучающийся,

Белорусский государственный университет

220013. Беларусь, Минск, пр. Независимости, 4

qiaodong@me.com

\section{(C) Люй Имин}

обучающийся,

Белорусский государственный университет

220013. Беларусь, Минск, пр. Независимости, 4

752776602@qq.com

\section{(C) Чжао Тин}

обучающийся,

Университет Лидса Беккета

Западный Йоркшир, Лидс

752776602@qq.com

Аннотация. Статья посвящена исследованию проблем финансового менеджмента и управления хозяйственной деятельностью в государственных медицинских учреждениях во время эпидемии Covid-19. Обоснована необходимость изменения ключевых элементов системы управления с учетом принципов и стратегий кризисного менеджмента. Выявляется необходимость реструктуризации ключевых систем управления больницами. На основании выявленных проблем и систематизации мирового опыта управления медицинскими учреждениями предлагаются некоторые меры (направления) совершенствования системы финансового обеспечения деятельности больниц во время чрезвычайных ситуаций по типу глобальной эпидемии, а также меры по налаживанию практики управления хозяйственной деятельности в условиях общественного кризиса: обновление системы экстренного финансирования в государственных больницах; создание организационной структуры управления финансами и хозяйственной деятельностью больниц в условиях чрезвычайной ситуации; разработка системы управления пожертвованиями в условиях чрезвычайной ситуации; создание плана служебной аттестации медицинского персонала в чрезвычайных условиях; усиление конструкции информатизации больницы.

Ключевые слова: менеджмент, управление, система управления, менеджмент в здравоохранении, менеджмент в больницах, управление больницами, государственные больницы, функционирование больниц, финансирование больниц, эпидемия Covid-19, кризисный менеджмент.

\section{Для цитирования}

Цяо Дун, Люй Имин, Чжао Тин. К вопросу о системе финансового менеджмента и управления хозяйственной деятельностью больниц во время эпидемии COVID-19 // 
Вестник Бурятского государственного университета. Экономика и менеджмент. 2021. № 4. С. 91-99.

Новая эпидемия коронной пневмонии Covid-19, всколыхнувшая весь мир в конце 2019 г. и продолжающаяся и сегодня, унесла с собой не только несколько миллионов человеческих жизней, но и продемонстрировала человечеству нестабильность существующей системы здравоохранения, ее неготовность к возникновению угроз столь глобального масштаба. Опыт разных стран по борьбе с эпидемией показывает, что вне зависимости от уровня экономического развития, политической системы большинству национальных правительств, увы, так и не удалось поддерживать экономическую жизнь общества, деятельность ключевых государственных институтов на прежнем уровне. И это при том, что во время такой чрезвычайной ситуации, как эпидемия Covid-19, функционирование государственного аппарата, его основных органов и систем должно быть как никогда слаженным и четким, ведь цена неверно принятых решений и несовершенства системы управления в таких кризисных условиях крайне высока.

Во время эпидемии Covid-19 больницы являются основным государственным органом, который должен обеспечивать заботу о здоровье и безопасность широких масс людей. Одним из важнейших вопросов деятельности больниц в период 2020-2021 гг. стал вопрос об эффективности финансирования и системы управления хозяйственной деятельностью $[2,3]$. В обстоятельствах чрезвычайной ситуации именно финансы больницы способны выступить гарантом удовлетворения потребностей населения в профилактике эпидемии и фактором стабильной и полноценной работы медицинского учреждения.

Несмотря на то, что к настоящему времени большинство государственных больниц выдержало испытание новой эпидемией коронной пневмонии и предоставило важный опыт управления глобальными чрезвычайными ситуациями, эпидемия обнажила многие проблемы в системе управления [4]. Грамотное и слаженное управление финансовыми вопросами учреждений здравоохранения является не только важной основой для предотвращения заболеваемости, но и эффективной гарантией повышения качества борьбы с эпидемиями в целом.

В рамках настоящей статьи обсуждается вопрос о необходимости совершенствования системы финансового менеджмента и практики управления хозяйственной деятельностью государственных больниц в условиях возникновения чрезвычайных ситуаций.

Основная часть. На фоне бушующей эпидемии новой коронной пневмонии внимание финансистов к построению эффективного менеджмента больниц значительно увеличилось. Китайский экономист-практик Цзинь Сичан (2020) сказал, что прежде чем заниматься выстраиванием эффективной системы финансового менеджмента в больнице, должна быть приведена в полное соответствие с экстренной ситуацией государственная политика и национальное управление в стране [2]. И с этим мнением довольно сложно не согласиться. Ци Чжендун и Лу Хаокуан (2020) считают, что правильное управление финансовыми средствами, а также пожертвованиями, поступающими в учреждения здравоохранения во время кризисных ситуаций, является важной частью профилактики эпидемии и борьбы с ней, залогом принятия правильных решений, реализации эффективной политики [3]. 
Цяо Дун, Люй Имин, Чжао Тин. К вопросу о системе финансового менеджмента и управления хозяйственной деятельностью больниц во время эпидемии COVID-19

«Эпидемия Covid-19 стала серьезной проверкой способности руководства и управления нашей страны, и выявила слабые места в системе общественного здравоохранения», - заявил 9 мая 2020 г. вице-министр Национальной комиссии здравоохранения КНР Ли Бинь. И это при том, что Китай является одной из самых крупнейших и высокоразвитых экономик мира [2].

В числе наиболее распространенных проблем, с которыми столкнулись больницы по всему миру во время эпидемии, - это проблемы неверного распределения финансовых ресурсов, несбалансированность ресурсов, слабая координация предпринимаемых действий, быстрорастущие медицинские потребности, проблема низких зарплат медицинских работников (особенно с учетом нормативных переработок всего медицинского персонала), проблемы с доступом к первичной медпомощи, низкий уровень квалификации терапевтов, а также огромный разрыв в качестве медицинского обслуживания между городами и регионами $[1,5,7]$. В силу вышеперечисленного многие медицинские учреждения оказались попросту не способны своевременно начать работать в местной системе контроля и профилактики заболеваний, оказывать помощь не только пациентам с пневмонией, но и другим людям, включая тех, кто обращался за помощью по другим вопросам [6].

Для того чтобы усилить способность государственных больниц к реагированию на чрезвычайные ситуации, такие как эпидемии, повысить способность удовлетворения фактических потребностей массового населения, необходимо создать такую систему финансирования их деятельности, которая была бы основана на международных нормах, опыте и существующих управленческих инновациях.

В рамках настоящей статьи нами были выделены некоторые направления, которые могут стать основой совершенствования политики финансового менеджмента и системы управления хозяйственной деятельностью медицинских учреждений для повышения эффективности их функционирования в условиях глобальных чрезвычайных ситуаций в области здравоохранения. Данные направления включают в себя следующие меры.

1. Обновить систему экстренного финансирования в государственных больнuйах.

В настоящее время в большинстве стран медицинские учреждения являются основным органом, отвечающим за предотвращение и контроль эпидемии, на них возлагается огромный объем обязанностей и ответственности, включая раннее предупреждение эпидемии, оказание помощи пострадавшим в амбулаторных условиях, лечение, инфекционный контроль, уменьшение социальных последствий эпидемии и т. д. При этом как внешняя, так и внутренняя среда больницы в условиях эпидемии претерпевают колоссальные изменения. Все это так или иначе приводит к определенным проблемам в обеспечении полноценной работы больницы, ее эффективном финансировании.

Отличительными особенностями чрезвычайной ситуации, обусловленной новой коронной пневмонией в 2020 г., вызвавшими трудности в управлении хозяйственной деятельностью больниц и реализации функций финансового менеджмента, стали длительная продолжительность эпидемии, события которой развязались в глобальном масштабе, огромное количество инфицированных людей, высокая скорость заражения и передачи вируса Covid-19. Все это так или иначе 
вызвало определенные сложности и ограничения в области финансирования, распределения ресурсов, правильного обращения с пожертвованиями [8]. Следовательно, финансовая система большинства больниц оказалась неспособной удовлетворять ключевые потребности населения в здравоохранении.

Фундаментальное решение данной проблемы заключается в том, что государственные больницы должны выстроить долгосрочную и эффективную финансовую систему, которая была бы применима в условиях чрезвычайных ситуаций, которая сможет многократно усилить возможности учреждения здравоохранения в плане реагирования на эпидемию и позволит обеспечить полноценное финансовое управление в условиях глобального общественного кризиса.

Основу системы экстренного финансирования государственных учреждений здравоохранения должны составлять такие принципы, как эффективность, стандартизация, предотвращение риска и защита. Выделяя принцип эффективности, мы имеем в виду прежде всего возможность медицинского учреждения быстро реагировать, формулировать меры чрезвычайной помощи и успешно осуществлять их реализацию.

Стандартизация финансирования больниц предполагает соответствие системы финансового менеджмента соответствующим нормативным требованиям компетентного вышестоящего органа с учетом мирового опыта.

Принцип предотвращения риска и опасности основан на том, что при реагировании на эпидемию и чрезвычайную ситуацию в области общественного здравоохранения система финансового менеджмента и управления хозяйственной деятельностью государственной больницы должна быть нацелена на достижение конечного результата - защита от риска и избежание риска.

2. Создать организационную структуру управления финансами и хозяйственной деятельностью больниц в условиях чрезвычайной ситуации.

Выделяя данное направление совершенствования деятельности государственных учреждений здравоохранения в условиях эпидемии, мы исходим прежде всего из того, что слаженная организационная структура больницы является основой для того, чтобы медицинское учреждение осуществляло комплексную полноценную деятельность в условиях чрезвычайной общественной ситуации, в том числе в области управления финансов.

С учетом мирового опыта, который был продемонстрирован больницами во время борьбы с эпидемией Covid-19, в основе организационной структуры медицинских учреждений должны быть три фундаментальных блока: главный, средний (внутренний) и вспомогательный. Каждый из этих блоков в условиях эпидемии должен нести ответственность за выполнение сугубо своих функций и обязанностей, конкретных задач [1].

В состав главного блока должен войти комитет по управлению деятельностью больницы в условиях чрезвычайных ситуаций. Это прежде всего «закулисная» группа, которая определяет долгосрочное стратегическое направление и общую стратегическую схему деятельности медицинского учреждения по предотвращению эпидемии, формирует соответствующую сеть управления финансами, которая будет способна обеспечить эффективный баланс разделения труда и сотрудничества, всестороннее и эффективное расширение прав и возможностей учреждения [5]. 
Цяо Дун, Люй Имин, Чжао Тин. К вопросу о системе финансового менеджмента и управления хозяйственной деятельностью больниц во время эпидемии COVID-19

Внутренний или средний блок организационной структуры больницы должен состоять из ответственных лиц, занимающихся общим управлением медицинским учреждением, руководством и координацией, планированием, выполнением основных обязанностей финансового управления в чрезвычайных ситуациях, формулированием конкретных мер по управлению финансами.

И, наконец, вспомогательный блок должен осуществлять экстренную деятельность всей больницы, уведомление ее о происходящих внутри и вне событиях. В состав данного блока должны быть включены такие отделы, как финансовый, информационный, аптечный и некоторые другие функциональные отделы, которые обеспечивают оперативный доступ к актуальной информации.

Основные обязанности финансового отдела в таком случае должны заключаться в реализации расчета с пациентами, предоставлении соответствующих гарантий, управлении больничными фондами, осуществлении бухгалтерского учета, калькуляции затрат. К тому же в состав обязанностей финансового отдела больницы в условиях чрезвычайной ситуации могут и должны войти задачи по подготовке и декларированию специального бюджета, прием и распределение пожертвований и т. д.

Зона ответственности информационного отдела должна быть сосредоточена на создании и защите разных систем экстренной информации для обеспечения бесперебойной работы информационной платформы медицинского учреждения.

В перечень основных обязанностей отдела оборудования следует включить работу по инвентаризации предметов первой необходимости с учетом особенностей возникшей чрезвычайной ситуации, а также закупку, приемку и управление складом оборудования и принадлежностей для оказания экстренной помощи в условиях глобальной эпидемии и в соответствии с потребностями конкретной больницы.

3. Разработать систему управления пожертвованиями в условиях чрезвычайной ситуаиии в области общественного здравоохранения.

Выделяя нормализацию внутренней системы управления пожертвованиями в качестве отдельного направления совершенствования практики управления хозяйственной и финансовой деятельностью медицинского учреждения, мы имеем в виду необходимость внедрения такого функционала, который позволил бы полноценно справиться с поступающими в больницу пожертвованиями в условиях общественного кризиса - глобальной эпидемии. Государственные больницы должны полностью учитывать срочность распределения материалов и разработать систему управления пожертвованиями в чрезвычайных ситуациях на основе существующей системы управления пожертвованиями, которая принята и реализуется в нормальных условиях функционирования учреждений здравоохранения.

В системе управления экстренным пожертвованием следует создать отдел управления пожертвованиями, уточнить централизованное управление пожертвованными материалами, стандартизировать процесс пожертвования и сформулировать конкретные требования и спецификации в звеньях приема материалов, регистрации, идентификации, хранения, доставки, заявки и раскрытию. Следует установить единую и стандартизированную систему регистрации пожертвованных материалов, обеспечить их идентификацию отделом управления материалами по уровню защиты и подлинности материалов, а также внедрить соответствующие стандарты распределения пожертвований в зависимости от их предна- 
значения и категории. Необходимо также усилить общий регламент управления материалами и создать стандартизированную библиотеку гарантийных материалов на случай чрезвычайных ситуаций.

Перед лицом внезапных эпидемических бедствий нехватка предметов первой необходимости оказала большее влияние на спасение пациентов и профессиональную защиту медицинского персонала. Все это свидетельствует о том, что повышение возможностей и уровня гарантии поставок предметов первой необходимости в государственных больницах, установление стандартизированной гарантии поставок, создание соответствующей библиотеки - все это ответная реакция, важная сила поддержки в случае серьезных чрезвычайных ситуаций в области общественного здравоохранения.

Гарантийный склад запасных материалов государственной больницы должен быть независимым от ежедневного управления материальными потоками и иметь отдельную бухгалтерскую книгу для управления. В соответствии с принципом: «первым пришел - первым ушел» - каждый отдел должен гарантировать динамический баланс аварийных запасов, что также позволит контролировать их расходы и стоимость. В то же время из-за наличия большого количества отделов и широкого спектра материалов правила и положения управления всем процессом аварийного хранения, использования и контроля материалов должны быть сформулированы так, чтобы улучшить общую координацию и координацию для обеспечения надежной, упорядоченной и непрерывной поставки аварийных чрезвычайно важных и необходимых материалов.

4. Разработать план служебной аттестачии медищинского персонала в условиях чрезвычайных ситуачий.

В те моменты, когда человеческие и медицинские ресурсы медицинского учреждения частично или полностью на исходе, изначально принятая политика по аттестации медицинского персонала должна быть скорректирована. В долгосрочной перспективе следует осуществить реформирование первоначального механизма оценки эффективности деятельности врачей, заранее разработать соответствующие планы по работе в условиях чрезвычайных ситуаций и сформулировать индикаторы оценки, которые могут корректироваться и настраиваться в зависимости от особенностей складывающейся ситуации.

Пересмотр политики порядка служебной аттестации должен быть осуществлен прежде всего в отношении тех медицинских работников, которые осмеливаются брать на себя ответственность, работают в условиях повышенного риска, выполняют тяжелые и интенсивные обязанности, которые работают сверхурочно и принимают активное участие в профилактике и борьбе с эпидемией. Для данных работников могут и должны быть предусмотрены соответствующие льготы, надбавки и субсидии, что обеспечит стабильность их последующей работы и повысит мотивацию в целом.

Что касается персонала, отвечающего за финансовую составляющую деятельности медицинского учреждения, то для них следует проводить обучение по освоению новой политики и реагирования в условиях чрезвычайной ситуации. В частности, речь идет о развитии у работников финансовых отделов аналитического мышления, управленческих способностей, профессиональных финансовых суждений, что позволит в условиях общественного кризиса и эпидемии своевременно предоставлять руководству больницы только самые актуальные, точные и 
Цяо Дун, Люй Имин, Чжао Тин. К вопросу о системе финансового менеджмента и управления хозяйственной деятельностью больниц во время эпидемии COVID-19

необходимые данные, грамотно использовать финансовые средства как силу и важный стратегический ресурс по предотвращению дальнейшего развития эпидемии.

5. Усиление конструкции информатизачии больнищь и создание полноценной адекватно функиионирующей платформы управления информационным ресурсом отдельного медичинского учреждения.

Эпидемия новой коронной пневмонии Covid-19 показала, что информационной системе в целом отводится огромное место и значение в управлении современными больницами. Все аспекты деятельности медицинского учреждения, особенно в условиях чрезвычайной ситуации, неотделимы от его информационной системы $[1,7]$.

В каждом отдельном учреждении здравоохранения должна быть создана своя платформа управления информацией, которая позволит разрушить все еще существующие сегодня информационные барьеры, складывающиеся между разными отделениями больницы, достичь высокой степени интеграции информации, оптимизировать эффективность обработки данных, реализовать эффективный сбор и сортировку данных, что, в свою очередь, значительно усилит общий управленческий эффект в больнице, сделает ее деятельность более систематизированной и регулируемой.

Помимо этого в век информационных технологий каждая больница вне зависимости от ее местоположения (город или регион) должна предоставлять населению бесконтактные услуги, включая платформу по диагностике заболевания, рекомендации по лечению, услуги медицинского страхования, выдачу электронных ваучеров на обследования, распределение лекарств. Это позволит пациентам получать оперативную диагностику и лечение в буквальном смысле, не выходя из дома, предоставит возможность полноценно решать свои проблемы в условиях серьезной чрезвычайной ситуации по типу эпидемии вирусной инфекции.

Таким образом, резюмируя вышесказанное, следует сказать, что национальные системы здравоохранения в большинстве стран нуждаются в реорганизации, повышении потенциала противодействия, степени готовности и скорости реагирования на чрезвычайные ситуации. Усиление финансового управления разными видами экономической деятельности, а также совершенствование управления хозяйственными системами больниц в особый период имеют решающее значение для своевременного реагирования на возникающие внутренние и внешние проблемы, угрозы в условиях развивающейся эпидемии и чрезвычайной ситуации в области здравоохранения. Финансовый персонал медицинского учреждения должен в точности понимать инновационные принципы обработки финансовых потоков, осуществления рабочих процедур, финансового надзора за деятельностью больницы. Только такой подход позволит обеспечить надежные финансовые гарантии в реализации максимально эффективных мероприятий по профилактике и контролю эпидемий.

\section{Литература}

1. Кризис Covid-19 и сектор здравоохранения // Отраслевая справка MOT. 2020. URL: https://www.ilo.org/wcmsp5/groups/public/---ed_dialogue/---sector/documents/briefingnote/ wcms_747870.pdf (дата обращения: 6.07.2021). Текст: электронный. 
2. Фу Шэньцзе. Говоря об инновациях в системе финансирования чрезвычайных ситуаций в государственных больницах в условиях серьезных чрезвычайных ситуаций в области общественного здравоохранения. 2021. (傅申洁 : 浅谈重大突发公共卫生事件下公立医院应急财务制度创新). Текст непосредственный.

3. Ху Хайфэн. Исследование вопросов финансового управления, связанных с экономическим бизнесом, в государственных больницах во время предотвращения крупных $\begin{array}{lllll}\text { эпидемий и } & \text { борьбы } & \text { с } & \text { ними. }\end{array}$ (公立医院在重大疫情防控期间有关经济业务的财务管理问题研究). Текст: непосредственный.

4. Garbey M., Joerger G., Shannon F., Fikfak V. (2020) A model of workflow in the hospital during a pandemic to assist management. PLoSONE 15(11). https://doi.org/10.1371/journal.pone.0242183 (дата обращения: 6.07.2021). Текст: непосредственный.

5. Hospital Experiences Responding to the COVID-19 Pandemic: Results of a National Pulse Survey March 23-27, 2020. URL: https:/oig.hhs.gov/oei/reports/oei-06-20-00300.pdf (дата обращения: 6.07.2021). Текст: электронный.

6. Leads: Lt Col Renee I. Matos and COL Kevin K. Chung, DoD Covid-19 Practice Management Guide: Clinical Management of COVID-19, 3-23-2020.Текст непосредственный.

7. Schmidt A. E. Abboud L. A., Bogaert P. (2021) Making the case for strong health information systems during a pandemic and beyond. Archives of Public Health. Volume 79 (13). Текст: непосредственный.

8. Toner E. Waldhorn R. (2020) What US Hospitals Should Do Now to Prepare for a COVID-19 Pandemic: Clinicians' Biosecurity News. URL: https://www.centerforhealthsecurity.org/cbn/2020/cbnreport-02272020.html (дата обращения: 6.07.2021).Текст: электронный.

Статья поступила в редакцию 02.08.2021; одобрена после рецензирования 29.10.2021; принята к публикации 01.11.2021

\section{ON THE SYSTEM OF FINANCIAL MANAGEMENT AND ECONOMIC ACTIVITY OF HOSPITALS DURING THE COVID-19 EPIDEMIC}

Qiao Dong

Student,

Belarusian State University

4 Nezavisimosti Prospect, Minsk, Belarus

qiaodong@me.com

\section{Lui Yiming}

Student,

Belarusian State University

4 Nezavisimosti Prospect, Minsk, Belarus

752776602@qq.com

\section{Zhao Ting}

Student,

Leeds Beckett University

West Yorkshire, Leeds, England

752776602@qq.com 
Цяо Дун, Люй Имин, Чжао Тин. К вопросу о системе финансового менеджмента и управления хозяйственной деятельностью больниц во время эпидемии COVID-19

Abstract. The article studies the problems of financial management and economic activities of public health facilities during the COVID-19 epidemic. We have substantiated the necessity of changing the key elements of the management system, taking into account the principles and strategies of crisis management. There is a need to restructure key hospital management systems. Based on the identified problems and the systematization of world experience in management of healthcare institutions, we have proposed some activities aimed at improving the system of financial support for the hospitals during emergencies like a global epidemic, as well as measures for regulation of economic activities in a social crisis, such as renewal of funding system in public hospitals, creation of an organizational structure for managing the finances and economic activities of hospitals in an emergency, development of a donation management system, establishment of an emergency performance appraisal plan for medical personnel, strengthening the hospital informatization structure.

Keywords: management, regulation, management system, healthcare management, hospital management, public health facilities, functioning of hospitals, hospital financing, the COVID-19 epidemic, crisis management.

\section{For citation}

Qiao Dong, Lui Yiming, Zhao Ting. On the System of Financial Management and Economic Activity of Hospitals During the COVID-19 Epidemic. Bulletin of Buryat State University. Economy and Management. 2021; 4: 91-99 (In Russ.).

The article was submitted 02.08.2021; approved after reviewing 29.10.2021; accepted for publication 01.11.2021. 